\title{
An epidemiological profile of otorhinolaryngological disorders in the patients attending ENT OPD of H.N.B Base teaching hospital of VCSGGRMS \& R I, Srinagar, Pauri, Garhwal
}

\author{
Mina $\mathbf{R}^{1}$, Bisht $\mathbf{R S}^{2}$, Sikarwar $\mathbf{V}^{3}$, Arya $\mathbf{A}^{4}$ \\ ${ }^{1}$ Dr Richa Mina, Senior Resident, ${ }^{2}$ Dr R S Bisht, Associate Professor, ${ }^{3}$ Dr Vikas Sikarwar, Assistant Professor, ${ }^{4}$ Dr Amit \\ Arya, Senior Resident. All authors are affiliated with Department of ENT, VCSGGMS \& RI and HNB Base Hospital, \\ Srinagar, Garhwal, Uttarakhand, India.
}

Address for Correspondence: Dr. Richa Mina, Senior Resident, Department of ENT, HNB Base Hospital, Srinagar, Garhwal, Uttarakhand, India, E-mail ID: richa.mina@me.com

\begin{abstract}
Background: ENT diseases are amongst most common causes for patient to report to hospital in both rural and urban setups. Since India is developing country with growing economy, its health system is still evolving. This study was done to assimilate the data on patients reporting to ENT OPD in past year so that the future treatment and trend of diseases could be studied and managed. It will help in further reconstruction of health care system of Pauri, Garhwal region. Objective: study conducted to determine the disease pattern and presentations of patients attending OPD of ENT department over a period of 1 year \& to study the variation in the disease patterns between the genders \& the age group in this region of the country. Material \& Method: This was a retrospective record based study was carried in the department of ENT. It included patients who had attended the OPD of ENT department of H.N.B Base teaching hospital of VCSGGRMS\&RI, Srinagar, Pauri Garhwal between $15^{\text {th }}$ July 2014 to $14^{\text {th }}$ July 2015 . Results: In this Study, we observed that males of younger age group constituted the maximum percentage. Among all the cases presenting to the OPD complaints were of ear being impacted wax, (H61.2) second was CSOM (H66.1-2). It was noticed that throat complaint was third complaint leading to OPD visits, in which acute pharyngitis was commonest. Conclusion: Impacted wax or cerumen is most common disease for seeking medical advice in our centre.
\end{abstract}

Key words: Chronic Suppurative Otitis Media, Epidemiology, Impacted wax

\section{Introduction}

Otorhinolaryngological care in the Garhwal region of Uttarakhand is still in a primitive stage. Otorhinolaryngological disorders are amongst the common reason for seeking medical advice in health care setup [1-2]. ENT disorders constitutes to one of the major cause of morbidity in any hilly area. In this part of country altitude, large pine forests, and poor socioeconomic condition of general population and lack of proper medical facilities further aggravate Otorhinolaryngological problems. The general population of Uttarakhand is slightly more than 10 million out of which $69.45 \%$ resides in rural set up. The female: male ratio of this region is $963: 1000$ [3]. There

Manuscript received: $9^{\text {th }}$ Nov 2015

Reviewed: $15^{\text {th }}$ Nov 2015

Author Corrected: $30^{\text {th }}$ Nov 2015

Accepted for Publication: $21^{\text {st }}$ Dec 2015 are only 3 tertiary referral hospitals in this state [3]. Our institute covers a vast population of Garhwal region of Uttarakhand state.

No such epidemiological data about the prevalence of Otorhinolaryngological disorder of this hilly region is available till now. The aim of this study was to define the epidemiologic profile of common Otorhinolaryngological disorders, in order the set guidelines to help general practitioners to deal with them in a primary care centre. Since the primary health care system is still evolving in this region, so patients seeking medical advice have to face considerable trouble in reaching appropriate medical facility. Due to gross shortage of doctors and facilities patients face many problems, the doctor patient ratio in India is 1:1800 [4] despite massive efforts from government to 
improve the situation. The burden on health care system in Uttarakhand is more as people have to travel a huge distances to avail proper treatment. Due to these unfavourable conditions and lack of proper guidance, the health care of general population is suffering. This data would help in guiding the primary health care professionals and training them for common diseases of this region, which would upgrade the health status of people.

The burden of disease on health care system and its impact on general well being is very high in this region. The analysis of 2000 for Global Burden of Disease (GBD) study stated that cause of morbidity (excluding injuries) is most commonly due to infectious diseases and common tropical diseases $60 \%, 27 \%$ due to lifestyle disorders and $13 \%$ due to potentially preventable per-natal conditions [5]. In studies, it has been stated that non-communicable diseases (NCDs) are leading cause of death globally [6]. It have been implicated that $40 \%$ of hospital stay and $35 \%$ of outpatient visits are due to NCDs [7]. In studies it has been noted that Otitis
Media and its seuelae are most common cause of preventable hearing loss in children in developing countries [8][9]. The major burden reported in India \& other developing countries by WHO is due to Chronic Suppurative Otitis Media [10].The previous studies states the prevalence trends to be slightly different from this study, but due a small population group, the data could vary. There is a very vast disparity according the region in incidence of ENT diseases [11].

\section{Methods and Material}

The study carried out in the patients who attended or referred to the OPD of department of ENT HNB Base hospital from $15^{\text {th }}$ July 2014 to $14^{\text {th }}$ July 2015. All patients attending the ENT OPD during last one year were included in this retrospective study. All patients categorized based on the age, gender and clinical diagnosis. The classification of the cases based on main symptom or clinical sign with which the patient presented to OPD. Diagnosis was coded according to the International Classification of Diseases (ICD -10)

\section{Results}

In this study group total number of patients of all reporting to ENT OPD were 8188 in time frame of 1 year. Out of which 4356 were males $53.19 \%$ and 3832 were females $46.84 \%$ (Table 1). The ratio of male: female in this study was $1.13: 1$.

Table 1: Distribution of patients

\begin{tabular}{|l|l|l|}
\hline Gender & Patients & \% \\
\hline Males & 4356 & 53.19 \\
\hline Females & 3832 & 46.84 \\
\hline Total & $\mathbf{8 1 8 8}$ & $\mathbf{1 0 0}$ \\
\hline
\end{tabular}

Out of the patients reporting to OPD most were followers of Hindu religion 96.25\% (7881) only 2\% (201) were Muslims and rest were Christians $1.25 \%$ (103) (Table 2).

Over all patients were in 0-10 years of age group 1632 i.e. $19.9 \%$, although it was noticed that in males same pattern was followed $12.31 \%$ (1008) but females predominantly fell into 31-40 years of age group 9.62\% (788). It was noticed in this study that $72.59 \%$ of patients were till age group 40 years after which the number has steady fallen to $2.49 \%$ for 71 and above age group.

Table 2: Involvement of Ear, Nose \& Throat

\begin{tabular}{|l|l|l|l|l|}
\hline Disease & M & F & Total & \% \\
\hline Ear & 2440 & 2220 & 4660 & 56.91 \\
\hline Nose & 616 & 464 & 1080 & 13.19 \\
\hline Throat\& neck & 1300 & 1148 & 2448 & 29.81 \\
\hline Total & $\mathbf{4 3 5 6}$ & $\mathbf{3 8 3 2}$ & $\mathbf{8 1 8 8}$ & $\mathbf{1 0 0}$ \\
\hline
\end{tabular}


In this study more than $50 \%$ of the patients came with diseases of ear $56.91 \%$ (4660), throat were $29.81 \%(2448)$ and nose in $13.19 \%$ (1080).

Table 3: Age Distribution

\begin{tabular}{|l|l|l|l|l|l|l|}
\hline Age group & $\mathbf{M}$ & $\mathbf{\%}$ & $\mathbf{F}$ & $\mathbf{\%}$ & Total & \% \\
\hline $\mathbf{0 - 1 0}$ & 1008 & 12.31 & 624 & 7.62 & 1632 & 19.9 \\
\hline $\mathbf{1 1 - 2 0}$ & 864 & 10.55 & 572 & 6.98 & 1436 & 17.53 \\
\hline $\mathbf{2 1 - 3 0}$ & 736 & 8.98 & 744 & 9.08 & 1480 & 18.07 \\
\hline $\mathbf{3 1 - 4 0}$ & 612 & 7.47 & 788 & 9.62 & 1400 & 17.09 \\
\hline $\mathbf{4 1 - 5 0}$ & 508 & 6.20 & 484 & 5.91 & 992 & 12.11 \\
\hline $\mathbf{5 1 - 6 0}$ & 376 & 4.59 & 340 & 4.15 & 716 & 8.74 \\
\hline $\mathbf{6 1 - 7 0}$ & 140 & 1.70 & 188 & 2.29 & 328 & 4.0 \\
\hline $\mathbf{7 1 +}$ & 112 & 1.36 & 92 & 1.12 & 204 & 2.49 \\
\hline Total & $\mathbf{4 3 5 6}$ & $\mathbf{5 3 . 1 6}$ & $\mathbf{3 8 3 2}$ & $\mathbf{4 6 . 8 4}$ & $\mathbf{8 1 8 8}$ & $\mathbf{1 0 0}$ \\
\hline
\end{tabular}

Ear: Most common cases were noted to be of impacted wax, which accounted for $1352(29.01 \%)$ of the total accounted OPD cases, mild female predominance was noted in it. It was noticed that in Females most common diagnosis was Wax or Cerumen impaction $684(14.67 \%)$ while in Males it was chronic suppurative otitis media 708 (15.19\%). Chronic suppurative otitis media is second most common cause of bringing patients to OPD, $1228(26.35 \%)$ patients.

Other diseases Otitis externa, Acute suppurative otitis media being 488 (10.47\%) \& $424(9.09 \%)$ respectively while Hearing Loss 300 (6.09\%), acute Mastoiditis 284 (6.09\%), Otomycosis 156 (3.34\%), Dermatitis of EAC 136 (2.91\%). Foreign Bodies of ear of all types were aggregated under 'Foreign body' column, 56 (1.12\%). Trauma to ear at any part and type were kept together under 'Trauma', they accounted for 52 cases (1.11\%). Facial palsy cases in form of Bell's Palsy,

Traumatic or complications were compiled in 'Facial Palsy' group which had $28(0.60 \%)$ patients \& and rest all non significant cases with chronic non specific pain with normal findings and investigations were kept together under 'NAD or others' group which accounted for $166(3.56 \%)$ patients. In this group female predominance by $94(2.01 \%)$ in comparison to $72(1.54 \%)$ of males were noticed.

All the patients attending OPD treated according to the treatment protocols.

Table 4: Disease wise distribution of patients [ Ear]

\begin{tabular}{|l|l|l|l|l|l|l|}
\hline DIAGNOSIS & MALE & \% & FEMALE & \% & TOTAL & \% \\
\hline Wax & 668 & 14.33 & 684 & 14.67 & 1352 & 29.01 \\
\hline CSOM & 708 & 15.19 & 520 & 11.15 & 1228 & 26.35 \\
\hline Otitis externa & 292 & 6.26 & 196 & 4.20 & 488 & 10.47 \\
\hline ASOM & 256 & 5.49 & 168 & 3.60 & 424 & 9.09 \\
\hline Hearing loss & 172 & 3.69 & 128 & 2.74 & 300 & 6.43 \\
\hline Ac Mastoiditis & 104 & 2.74 & 180 & 3.86 & 284 & 6.09 \\
\hline Otomycosis & 48 & 1.03 & 108 & 2.31 & 156 & 3.34 \\
\hline Dermatitis EAC & 48 & 1.03 & 88 & 1.88 & 136 & 2.91 \\
\hline Foreign body & 36 & 0.77 & 20 & 0.42 & 56 & 1.12 \\
\hline Trauma & 24 & 0.51 & 28 & 0.60 & 52 & 1.11 \\
\hline Facial Palsy & 12 & 0.25 & 16 & 0.55 & 28 & 0.60 \\
\hline NAD/ Others & 72 & 1.54 & 94 & 2.01 & 166 & 3.56 \\
\hline TOTAL & $\mathbf{2 4 4 0}$ & $\mathbf{5 2 . 3 6}$ & $\mathbf{2 2 2 0}$ & $\mathbf{4 7 . 6 3}$ & $\mathbf{4 6 6 0}$ & $\mathbf{1 0 0}$ \\
\hline
\end{tabular}


Nose: It was noted that nasal complaints were least of all cause of bringing patients to OPD $1080(13.19 \%)$ out of which $616(57.03 \%)$ were males and 464 (42.96\%) were females. Amongst all nasal diseases Deviated nasal septum (DNS) was most common being $144(13.33 \%)$ in males \& $100(9.25 \%)$ in females overall 244 patients were there which accounted for $22.59 \%$. Second commonest disease of nose found to be Epistaxis 216 (20\%) out of which 140 (12.96\%) were males and $76(7.03 \%)$ were females. Acute rhinitis accounted for 124 patients $11.48 \%$, Vestibulitis was seen in 92 patients $8.51 \%$, and Chronic Rhinosinusitis accounted for 128 patients $11.85 \%$. Diseases like Allergic Rhinitis, Foreign Body, Chronic dacrocystitis was 104 (9.62\%), 76 (7.03\%) and $56(5.18 \%)$ respectively. All the diseases with non-specific pain of nose and face with normal examination and investigations were kept in 'Other' group which had 40 (3.70\%) patients out of which $16(1.48 \%)$ were males and $24(2.22 \%)$ were females. A slight female predilection was noticed in this group.

Table 5: Disease wise distribution of patients [Nose]

\begin{tabular}{|l|l|l|l|l|l|l|}
\hline Diagnosis & Males & $\mathbf{\%}$ & Females & \% & Total & \% \\
\hline DNS & 144 & 13.33 & 100 & 9.25 & 244 & 22.59 \\
\hline Epistaxix & 140 & 12.96 & 76 & 7.03 & 216 & 20 \\
\hline Acute Rhinitis & 80 & 7.40 & 44 & 4.07 & 124 & 11.48 \\
\hline Vestibulitis & 60 & 5.55 & 32 & 2.96 & 92 & 8.51 \\
\hline $\begin{array}{l}\text { Chronic } \\
\text { Rhinosinusitis }\end{array}$ & 56 & 5.18 & 72 & 6.66 & 128 & 11.85 \\
\hline Allergic Rhinitis & 56 & 5.18 & 48 & 4.44 & 104 & 9.62 \\
\hline Foreign Body & 44 & 4.07 & 32 & 2.96 & 76 & 7.03 \\
\hline Chronic Dacrocystitis & 20 & 1.85 & 36 & 3.33 & 56 & 5.18 \\
\hline Others & 16 & 1.48 & 24 & 2.22 & 40 & 3.70 \\
\hline Total & $\mathbf{6 1 6}$ & $\mathbf{5 7 . 0 3}$ & $\mathbf{4 6 4}$ & $\mathbf{4 2 . 9 6}$ & $\mathbf{1 0 8 0}$ & $\mathbf{1 0 0}$ \\
\hline
\end{tabular}

Throat:-The complaints of throat were evaluated and it was noticed that most common symptom was throat pain and disease was acute pharyngitis $988(40.35 \%)$ out of which $568(23.20 \%)$ were males and $420(17.15 \%)$ were females. Neck swelling was seen in $316(12.90 \%)$ of patients, GERD was $296(12.09 \%)$, stomatitis occurred in $288(11.76 \%)$ of patients, acute tonsillitis in $284(11.60 \%)$. It was seen that thyroid swelling,growth or neoplasia and parotid swelling was in $68(2.77 \%), 72(2.94 \%)$ and $40(1.63 \%)$ respectively. All the patients with growth at any site were kept together in Growth/ neoplasia group since the confirmed diagnosis could only be made after further investigations only. In 'Others' group had the various cases, which were encountered in very less in our set up which comprised of 96 (3.92\%).

Table 6: Disease wise distribution of patients [Pharynx]

\begin{tabular}{|l|l|l|l|l|l|l|}
\hline Diagnosis & Males & $\mathbf{\%}$ & Females & \% & Total & \% \\
\hline Acute Pharyngitis & 568 & 23.20 & 420 & 17.15 & 988 & 40.35 \\
\hline Neck swelling & 132 & 5.39 & 184 & 7.51 & 316 & 12.90 \\
\hline GERD & 156 & 6.37 & 140 & 5.71 & 296 & 12.09 \\
\hline Stomatitis & 128 & 5.22 & 160 & 6.53 & 288 & 11.76 \\
\hline Acute Tonsillitis & 164 & 6.69 & 120 & 4.90 & 284 & 11.60 \\
\hline Thyroid Swelling & 56 & 2.28 & 12 & 0.49 & 68 & 2.77 \\
\hline Growth / neoplasia & 40 & 1.63 & 32 & 1.30 & 72 & 2.94 \\
\hline Parotid Swelling & 20 & 0.81 & 20 & 0.81 & 40 & 1.63 \\
\hline Others & 36 & 1.47 & 60 & 2.45 & 96 & 3.92 \\
\hline Total & $\mathbf{1 3 0 0}$ & $\mathbf{5 3 . 1 0}$ & $\mathbf{1 1 4 8}$ & $\mathbf{4 6 . 8 9}$ & $\mathbf{2 4 4 8}$ & $\mathbf{1 0 0}$ \\
\hline
\end{tabular}

\section{Discussion}

The current study shows that most of the patients were from age group 0-10 years, which collaborates with findings in other studies, as young age group is most common age group to seek medical advice in ENT field [12-13]. Male: Female ratio of study is $1.13: 1$ which 
could be due to Male predominance in population of India. Uttarakhand region consists of Hindu dominant society so similar findings were noticed that in our study. The census of state shows Hindu population to be $72.1 \%$, Muslim population $10.1 \%$ and Christians to be $0.27 \%$. Although the distribution was similar but statistics were different in our study with Hindu being 96.25\%, Muslims $2.49 \%$ and Christians in $1.25 \%$. The variation noticed in our study from general census could be due regional variations and small population size on the study.

This study shows Ear diseases to be most common in seeking medical advice especially in younger age group. Most common disease was impacted wax or cerumen in EAC $16.51 \%$, WHO census also shows Wax or impacted Cerumen to be most common cause of reversible hearing loss in our country [14]. Although our study has shown CSOM to be second common $14.99 \%$ cause otherwise most common disease of ear in developing countries is CSOM, which is further leading to a major burden on health care system and society [15-16].

In our study, DNS was most common disease of nose while in other studies it was noted that allergic rhinitis is most upcoming disease [13]. Due to increase in pollution allergic rhinitis and its comorbidities are on rising trend but DNS was major disease in this region may be due to rural background of this region.

Throat pain was leading cause of bringing patients to hospital in which acute pharyngitis was leading disease. It's a well known fact that infection pathology in disease is common in developing countries due to inadequate resources, improper treatment, incomplete investigations, improper follow-up nutritional deficiencies and overburdened health care system. Due to above reasons infectious diseases are still leading cause of morbidity and mortality in developing country.

In future, another study can plan for longer duration. Data from all leading referral hospitals of this region should be compiled so that population of whole of Uttarakhand is targeted in the study. The data should also have a log on treatment given to the patient so that accurate treatment protocols should be prepared.

\section{Conclusion}

From the data compiled in this study common ENT complaints should be evaluated for their cause and available treatment to reduce the burden on tertiary health care centres. The health workers and primary health care centres should be trained to deal with basic diseases and rehabilitation so that in ENT specialists could deal health camps surgical management.

If this model health care system could be implemented in this region, then the primary health in rural population would be improved and burden on government and society would reduce. This health care protocol if followed then it would be beneficial especially for Uttarakhand region where due to inaccessibility, lack of awareness and rehabilitation options ENT health of general population is poor.

\section{Funding:Nil. Conflict of interest: Nil. Permission for IRB: Yes}

\section{References}

1. Adam DJ, Bain M, Shanks E, Bradbury AW. Geographical inequality in the provision of carotid endarterectomy in Scotland. Scottish Vascular Audit Group. Br J Surg. 1998 Aug;85(8):1075-9.

2. A. McCormick, D. Fleming, and J. Charlton, "Morbidity statistics from general practice," in 4th National Study 1992-1993, Office of National Statistics, HMSO, London, UK, 1995.

3. Uttrakhand: at a Glance 2013-14 (12 ${ }^{\text {th }}$ edition), Directorate of Economics and Statistics, Dehradun. Pgs 7-8.( available at : www.uk.gov.in/pages/display/115state-profile)

4. Deo MG. "Doctor population ratio for India - the reality". Indian J Med Res. 2013 Apr;137(4):632-5.

5. Srinivisan R. Health Care in India- Vision 2020. Issues and Prospects. (Available atwww.planningcommission.nic.in/reports/genrep/.../26_ bg2020.doc)

6. Ministry of Health and Family Welfare. Economic burden of tobacco related diseases in India. (Available at-

http://www.searo.who.int/india/topics/tobacco/economi c_burden_of_tobacco_related_diseases_in_india_execut ive_summary.pdf)

7. Bloom, D.E., Cafiero-Fonseca E.T., Candeias V, Adashi E., Bloom L., Gurfein L., Jané-Llopis E., Lubet, 
A., Mitgang E, Carroll O’Brien J, Saxena A (2014). Economics of Non-Communicable Diseases in India: The Costs and Returns on Investment of Interventions to Promote Healthy Living and Prevent, Treat, and Manage NCDs. World Economic Forum, Harvard School of Public Health, 2014.Pg 13. (Available athttp://www3.weforum.org/docs/WEF_Economic

NonCommunicableDiseasesIndia_Report_2014.pdf.)

8. Kishve SP, Kumar N, Aarif SSM,Kalakoti P. Ear, nose and throat disorders in paediatric patients at a rural hospital in India. Australasian Medical Journal, 2010; 3(12):786-790.

9. Zakzouk SM, Jamal TS, Daghistani KJ. Epidemiology of acute otitis media among Saudi children. Int $\mathrm{J}$ Pediatr Otorhinolaryngol. 2002 Feb 25;62(3):219-22.

10. Child and Adolescent Health and Development Prevention of Blindness and Deafness. World Health Organization, Geneva, Switzerland, 2004.

11. Khan AR, Khan SA, Arif AU, Waheed R. Analysis of ENT diseases at Khyber Teaching Hospital, Peshawar. J Med Sci 2013;21(1)7-9.

12. Symvoulakis EK, Klinis S, Alegakis A, Kyrmizakis DE, Drivas EI, Rachiotis G, Philalithis A, Velegrakis
GA. Epidemiologic profile of otorhinolaryngological, head and neck disorders in a tertiary hospital unit in Greece: a challenge for general practitioners? BMC Ear Nose Throat Disord. 2006 Jun 7;6:12.

13. Emerson LP, Job A, Abraham V. A model for provision of ENT health care service at primary and secondary hospital level in a developing country. Biomed Res Int. 2013;2013:562643. doi: 10.1155/2013/562643. Epub 2013 Sep 3.

14. World Health Organization. State of hearing and ear care in the South East Asia Region. WHO Regional Office for South East Asia. WHO-SEARO. SEA/Deaf/9. (Available at http://www.searo.who.int/LinkFiles/Publications_ HEARING_\&_EAR_CARE.pdf).

15. Gupta A, Gupta. A study of prevalence of complications of suppurative otitis media in rural area of Loni. Ind J Otol 1996;2:177-83.

16. Akinpelu OV, Amusa YB, Komolafe EO, Adeolu AA, Oladele AO, Ameye SA. Challenges in management of chronic suppurative otitis media in a developing country. J Laryngol Otol. 2008 Jan;122(1):16-20. Epub 2007 May 22.

\section{How to cite this article?}

Mina R, Bisht RS, Sikarwar V, Arya A. An epidemiological profile of otorhinolaryngological disorders in the patients attending ENT OPD of H.N.B Base teaching hospital of VCSGGRMS \& R I, Srinagar, Pauri, Garhwal. Int J Med Res Rev 2015;3(11):1333-1338. doi: 10.17511/ijmrr.2015.i11.242. 